\title{
Alternation of the Autonomic Nervous System Is Associated With Pulmonary Sequelae in Patients With COVID-19 After Six Months of Discharge
}

Tao Bai't, Dan Zhou' ${ }^{1+}$, Feierkaiti Yushanjiang ${ }^{2}$, Dongke Wang ${ }^{1}$, Dongmei Zhang ${ }^{3}$, Xinghuang Liu' ${ }^{1}$, Jun Song', Jianchu Zhang ${ }^{3}$, Xiaohua Hou ${ }^{1 *}$ and Yanling Ma ${ }^{3 *}$

\begin{abstract}
1 Division of Gastroenterology, Union Hospital, Tongji Medical College, Huazhong University of Science and Technology, Wuhan, China, ${ }^{2}$ Xinjiang Medical University, Ürümqi, China, ${ }^{3}$ Key Laboratory of Pulmonary Diseases of Health Ministry, Department of Respiratory and Critical Care Medicine, Union Hospital, Tongji Medical College, Huazhong University of Science and Technology, Wuhan, China
\end{abstract}

OPEN ACCESS

Edited by:

Sheng Wang,

Hebei Medical University, China

Reviewed by:

Wei-Zhong Wang,

Second Military Medical University,

China

Baojian Xue,

The University of lowa, United States

${ }^{*}$ Correspondence:

Xiaohua Hou

houxh@hust.edu.cn

Yanling Ma

mayanling811@hust.edu.cn

tThese authors have contributed equally to this work and share first authorship

Specialty section:

This article was submitted to Autonomic Neuroscience, a section of the journal Frontiers in Physiology

Received: 31 October 2021 Accepted: 26 November 2021 Published: 21 January 2022

Citation:

Bai T, Zhou D, Yushanjiang $F$, Wang $D$, Zhang $D$, Liu X, Song J, Zhang J, Hou $X$ and Ma $Y$ (2022) Alternation of the Autonomic Nervous System Is Associated With Pulmonary Sequelae in Patients With COVID-19 After Six Months of Discharge.

Front. Physiol. 12:805925. doi: 10.3389/fphys.2021.805925
Previous studies suggest that autonomic dysfunction is associated with disease severity in acute phase in patients with coronavirus disease 2019 (COVID-19). However, the association between autonomic dysfunction and pulmonary sequelae in patients with COVID-19 is unknown. We conducted a prospective study to investigate the association between autonomic dysfunction and pulmonary sequelae in patients with COVID-19 discharged for 6 months. We included 40 eligible participants and collected the following indicators: heart rate variability (HRV), pulmonary function tests (PFTs), lung X-ray computed tomography $(\mathrm{CT})$, routine blood parameters, liver function parameters, and lymphocyte subsets. We found that at 6 months post-discharge, HRV still had a tight correlation with pulmonary fibrosis. There was a significant difference in HRV between patients with and without diffusion dysfunction, but HRV did not differ between patients with or without ventilatory dysfunction. Diffusion dysfunction and pulmonary fibrosis were tightly associated, and HRV index changes in patients with diffusion dysfunction had the same trend as that of patients with pulmonary fibrosis. They had a lower standard deviation of NN intervals (SDNN), the standard deviation of the average NN intervals (SDANN), and the triangular index, but a higher ratio between LF and HF power (LF/HF). In addition, WBC, neutrophils, and CD4/CD8 were correlated with pulmonary fibrosis and HRV. We concluded that autonomic dysfunction is closely associated with pulmonary fibrosis and diffusion dysfunction, and immune mechanisms may potentially contribute to this process.

\footnotetext{
Keywords: COVID-19, pulmonary sequelae, heart rate variability, pulmonary diffusion dysfunction, autonomic nervous system
}

\section{INTRODUCTION}

According to the Coronavirus Resource Center at Johns Hopkins University, the global pandemic caused by coronavirus disease 2019 (COVID-19) has affected more than 230 million people. There have been more than 4.4 million deaths, and 180 million people have recovered (Lewis et al., 2021; Safont et al., 2021). With such a significant recovered population, we must be concerned about the long-term lung damage caused by COVID-19 infection (Zhao et al., 2020). 
The main pulmonary sequelae in patients with COVID-19 after discharge are pulmonary fibrosis and diffusion dysfunction, but mechanisms are unclear (Huang et al., 2021). Pulmonary fibrosis can seriously affect the quality of life of patients and impose a heavy financial burden on them (Lee et al., 2020; Leung et al., 2020). Its median survival is 3-5 years after diagnosis and is highly correlated with treatment (Meyer, 2017). So, early identification and intervention of pulmonary fibrosis are essential to improve the quality of survival. Heart rate variability (HRV) is the most valuable non-invasive test to assess the function of the autonomic nervous system (ANS; Ahmad et al., 2009). Some researchers found that ANS dysfunction appeared early in patients with COVID-19. In addition, even under the influence of factors, such as hypoxia and stress, HRV was still associated with the severity of patients in the acute phase (Natarajan et al., 2020; Luong et al., 2021). Severe patients without improved HRV needed longer to clear the virus and recover, indicating that HRV can be used as a non-invasive predictor for short-term clinical outcomes (Pan et al., 2021). Meanwhile, some studies suggest that the immune system is associated with long-term autonomic disorders and pulmonary sequelae in patients with COVID-19 (Kenney and Ganta, 2014; Hasty et al., 2021; Wang et al., 2020; Wu et al., 2021). However, we do not know whether there are associations between long-term autonomic disorders and pulmonary sequelae (Wang et al., 2020; Dani et al., 2021; McDonald, 2021).

In this study, we aimed to discuss the association between ANS dysfunction and pulmonary fibrosis sequelae. All the postdischarge patients were within normal limits for all physiological indicators, so HRV can more accurately and credible evaluate the function of the ANS.

\section{MATERIALS AND METHODS}

\section{Study Design and Participants}

In this prospective study, we included 40 patients who had been hospitalized at the Union Hospital, Tongji Medical College, Huazhong University of Science and Technology between January 10 and February 10, 2020, for COVID-19 infection, and data were counted at 6 months after their discharge from the hospital. Demographics, clinical characteristics, pulmonary function tests, lung X-ray computed tomography (CT), and HRV were collected in the included patients. The study was approved by the Ethics Committee of the United Hospital. All patients included in this prospective study provided written informed consent at the time of admission.

\section{Demographics and Clinical Data}

We recorded demographic characteristics [e.g., age, gender, and body mass index (BMI)] and detailed clinical data, such as postdischarge clinical symptoms (e.g., fever, cough, and diarrhea), routine blood parameters [e.g., white blood cell (WBC), red blood cell (RBC), and the mean corpuscular hemoglobin concentration (MCHC)], liver function parameter (e.g., aspartate transaminase (AST), alanine transaminase (ALT), and AST/ALT) were assessed in all patients. We invited all patients to participate in the immune system examination, but only 24 participants agreed
TABLE 1.1 | Clinical characteristics of all patients and grouped by ventilatory dysfunction.

\begin{tabular}{|c|c|c|c|c|}
\hline \multirow[t]{2}{*}{ Variable } & \multirow{2}{*}{$\begin{array}{c}\text { Total } \\
(N=40)\end{array}$} & \multirow{2}{*}{$\begin{array}{c}\begin{array}{r}\text { No ventilatory } \\
\text { dysfunction }\end{array} \\
(N=33)\end{array}$} & \multirow{2}{*}{$\begin{array}{c}\begin{array}{c}\text { With ventilation } \\
\text { dysfunction }\end{array} \\
(N=7)\end{array}$} & \multirow[t]{2}{*}{$P$ value } \\
\hline & & & & \\
\hline Sex (male), N (\%) & 17 (42.5\%) & 15 (45.5\%) & $2(28.6 \%)$ & 0.577 \\
\hline Age, Mean, year & $55.1 \pm 13.9$ & $53.1 \pm 13.5$ & $64.1 \pm 11.8$ & 0.162 \\
\hline $\mathrm{BMI}$ & $25.4 \pm 2.5$ & $25.7 \pm 2.6$ & $24 \pm 0.4$ & 0.807 \\
\hline $\begin{array}{l}\text { Clinical typing of } \\
\text { severe and above }\end{array}$ & $14(35 \%)$ & $10(30.3 \%)$ & $4(57 \%)$ & 0.401 \\
\hline Have ARDS & $21(52.5 \%)$ & $20(60.6 \%)$ & $1(14.3 \%)$ & 0.754 \\
\hline Drinking history & $2(5 \%)$ & $2(6.1 \%)$ & $0(0 \%)$ & 0.058 \\
\hline Smoking history & $7(17.5 \%)$ & $7(21.1 \%)$ & $0(0 \%)$ & 0.137 \\
\hline $\begin{array}{l}\text { History of } \\
\text { cardiopulmonary } \\
\text { disease }\end{array}$ & $5(12.5 \%)$ & $4(12.1 \%)$ & $1(14.3 \%)$ & 0.945 \\
\hline $\begin{array}{l}\text { History of heart } \\
\text { disease }\end{array}$ & $14(35 \%)$ & 12 (36.3\%) & $2(28.5 \%)$ & 0.754 \\
\hline $\begin{array}{l}\text { History of } \\
\text { hyperlipidemia }\end{array}$ & $12(30 \%)$ & 7 (21.2\%) & 5 (71.4\%) & 0.037 \\
\hline $\begin{array}{l}\text { History of Type } 2 \\
\text { diabetes }\end{array}$ & $6(15 \%)$ & $4(12.1 \%)$ & $2(28.5 \%)$ & 0.507 \\
\hline \multicolumn{5}{|l|}{$\begin{array}{l}\text { Post-discharge } \\
\text { symptoms and } \\
\text { signs, n (\%) }\end{array}$} \\
\hline Fever & $1(2.5 \%)$ & $1(3 \%)$ & $0(0 \%)$ & 0.937 \\
\hline Cough & $12(30 \%)$ & $12(36.3 \%)$ & $0(0 \%)$ & 0.228 \\
\hline Breathing difficulties & 17 (42.5\%) & 12 (36.4\%) & $4(57.1 \%)$ & 0.425 \\
\hline Diarrhea & $8(20 \%)$ & $6(18.1 \%)$ & $2(28.6 \%)$ & 0.425 \\
\hline Muscle pain & $10(25 \%)$ & 9 (27.9\%) & $1(14.3 \%)$ & 0.843 \\
\hline $\begin{array}{l}\text { Pulmonary fibrosis, } \\
\text { n (\%) }\end{array}$ & 23 (57.5\%) & $16(48.5 \%)$ & $7(100 \%)$ & 0.107 \\
\hline \multicolumn{5}{|l|}{ CT findings (\%) } \\
\hline Ground glass & - & - & $2(28.6 \%)$ & - \\
\hline Opacity fiber & - & - & 7 (100\%) & - \\
\hline Streak shadow & - & - & 2 (28.6\%) & - \\
\hline $\begin{array}{l}\text { Tractive } \\
\text { bronchiectasis } \\
\text { reticulation }\end{array}$ & - & - & $2(28.6 \%)$ & - \\
\hline $\begin{array}{l}\text { Bronchovascular } \\
\text { bundle distortion }\end{array}$ & - & - & $1(14.3 \%)$ & - \\
\hline
\end{tabular}

to complete, such as lymphocyte subsets (e.g., CD4, CD8, and CD4/CD8). Our method of detecting lymphocyte subsets is using flow cytometry, the flow cytometer we used was the FACS Canto (BD, United States) and the reagent test kit used was the Lymphocytes Subgroup Typing Kit (Human) produced by BD Medical Devices (Shanghai) Co., Ltd. (Shanghai, China). The severity of illness, presence of acute respiratory distress syndrome (ARDS) in acute phase of COVID-19 and past medical history of each participant were retrieved from the electronic medical record of hospital. The diagnosis and disease severity of COVID19 of all patients were based on the New Coronavirus Pneumonia Diagnosis and Treatment Plan (Trial 7) (Jing-Ya et al., 2020). The diagnosis of ARDS of all patients were based on the AmericanEuropean Consensus Conference on ARDS (Fan et al., 2018). Past medical history includes: type 2 diabetes, hyperlipidemia, heart disease, and cardiopulmonary disease. 
TABLE 1.2 | Clinical characteristics of all patients and grouped by diffusion dysfunction.

\begin{tabular}{|c|c|c|c|c|c|c|c|c|c|}
\hline \multirow[t]{2}{*}{ Variable } & Total & $\begin{array}{l}\text { No diffusion } \\
\text { dysfunction }\end{array}$ & $\begin{array}{l}\text { With diffusion } \\
\text { dysfunction }\end{array}$ & $P$ value & Variable & Total & $\begin{array}{c}\text { No pulmonary } \\
\text { fibrosis }\end{array}$ & $\begin{array}{l}\text { With pulmonary } \\
\text { fibrosis }\end{array}$ & $P$ value \\
\hline & $(N=40)$ & $(N=18)$ & $(N=22)$ & & & $(N=40)$ & $(N=17)$ & $(N=23)$ & \\
\hline Sex (male), N (\%) & 17 (42.5\%) & $14(77.8 \%)$ & $3(13.7 \%)$ & 0.039 & Sex (male), N (\%) & $17(42.5 \%)$ & 14 (82.4\%) & $N=3(13.0 \%)$ & 0.432 \\
\hline Age, Mean, year & $55.1 \pm 13.9$ & $46.6 \pm 13.2$ & $62.0 \pm 9.7$ & 0.001 & Age, Mean, year & $55.1 \pm 13.9$ & $54.1 \pm 12.9$ & $59.7 \pm 12.5$ & 0.018 \\
\hline $\mathrm{BMI}$ & $25.4 \pm 2.5$ & $25.7 \pm 2.1$ & $24.8 \pm 2.5$ & 0.299 & $\mathrm{BMI}$ & $25.4 \pm 2.5$ & $25.7 \pm 2.1$ & $25.4 \pm 2.7$ & 0.432 \\
\hline $\begin{array}{l}\text { Clinical typing of severe } \\
\text { and above }\end{array}$ & $26(65 \%)$ & 10 (55.6\%) & 16 (72.7\%) & 0.352 & $\begin{array}{l}\text { Clinical typing of severe } \\
\text { and above }\end{array}$ & $26(65 \%)$ & 10 (55.6\%) & $16(72.7 \%)$ & 0.277 \\
\hline Have ARDS & $21(52.5 \%)$ & $8(44.4 \%)$ & $13(59 \%)$ & 0.443 & Have ARDS & $21(52.5 \%)$ & $8(44.4 \%)$ & $13(59 \%)$ & 0.626 \\
\hline Drinking history & $2(5 \%)$ & $2(11.1 \%)$ & $0(0 \%)$ & 0.563 & Drinking history & $2(5 \%)$ & $2(11.1 \%)$ & $0(0 \%)$ & 0.533 \\
\hline Smoking history & 7 (17.5\%) & $5(27.8 \%)$ & $2(9.1 \%)$ & 0.325 & Smoking history & $7(17.5 \%)$ & $5(27.8 \%)$ & $2(9.1 \%)$ & 0.588 \\
\hline $\begin{array}{l}\text { History of } \\
\text { cardiopulmonary } \\
\text { disease }\end{array}$ & $5(12.5 \%)$ & $3(16.7 \%)$ & $2(9.1 \%)$ & 0.904 & $\begin{array}{l}\text { History of } \\
\text { cardiopulmonary } \\
\text { disease }\end{array}$ & $5(12.5 \%)$ & $3(16.7 \%)$ & $2(9.1 \%)$ & 0.957 \\
\hline History of heart disease & $14(35 \%)$ & $4(22.2 \%)$ & $10(45.5 \%)$ & 0.219 & History of heart disease & $14(35 \%)$ & $4(22.2 \%)$ & $10(45.5 \%)$ & 0.165 \\
\hline $\begin{array}{l}\text { History of } \\
\text { hyperlipidemia }\end{array}$ & $12(30 \%)$ & $3(16.7 \%)$ & $9(40.1 \%)$ & 0.199 & $\begin{array}{l}\text { History of } \\
\text { hyperlipidemia }\end{array}$ & $12(30 \%)$ & $3(16.7 \%)$ & $9(40.1 \%)$ & 0.090 \\
\hline $\begin{array}{l}\text { History of type } 2 \\
\text { diabetes }\end{array}$ & $6(15 \%)$ & $5(27.8 \%)$ & $1(4.5 \%)$ & 0.366 & $\begin{array}{l}\text { History of type } 2 \\
\text { diabetes }\end{array}$ & $6(15 \%)$ & $5(27.8 \%)$ & $1(4.5 \%)$ & 0.401 \\
\hline $\begin{array}{l}\text { Post-discharge } \\
\text { symptoms and signs, } \\
\text { n (\%) }\end{array}$ & & & & & $\begin{array}{l}\text { Post-discharge } \\
\text { symptoms and signs, } \\
\text { n (\%) }\end{array}$ & & & & \\
\hline Fever & $1(2.5 \%)$ & $0(0 \%)$ & $1(4.3 \%)$ & 0.829 & Fever & $1(2.5 \%)$ & $0(0 \%)$ & $1(4.3 \%)$ & 0.829 \\
\hline Cough & $12(30 \%)$ & $5(27.8 \%)$ & $7(31.8 \%)$ & 0.626 & Cough & $12(30 \%)$ & $5(27.8 \%)$ & $7(31.8 \%)$ & 0.957 \\
\hline Breathing difficulties & $16(40 \%)$ & $5(27.8 \%)$ & $11(50 \%)$ & 0.665 & Breathing difficulties & 17 (42.5\%) & $4(23.5 \%)$ & $13(56.5 \%)$ & 0.329 \\
\hline Diarrhea & $8(20 \%)$ & $3(16.6 \%)$ & $5(22.7 \%)$ & 0.745 & Diarrhea & $8(20 \%)$ & $3(16.6 \%)$ & $5(22.7 \%)$ & 0.829 \\
\hline Muscle pain & $10(25 \%)$ & $4(22.2 \%)$ & $6(27.2 \%)$ & 0.685 & Muscle pain & $10(25 \%)$ & $4(22.2 \%)$ & $6(27.2 \%)$ & 0.134 \\
\hline Pulmonary fibrosis, $\mathrm{n}$ & $23(57.5 \%)$ & $3(16.7 \%)$ & $20(90.1 \%)$ & $P<0.01$ & CT findings (\%) & & & & \\
\hline$(\%)$ & & & & & Ground glass & $-\&$ & - & $7(30.4 \%)$ & - \\
\hline CT findings (\%) & & & & & Opacity fiber & - & - & $20(86.9 \%)$ & - \\
\hline Ground glass & - & - & $7(31.8 \%)$ & - & Streak shadow & - & - & $4(17.3 \%)$ & - \\
\hline Opacity fiber & - & - & 19 (86.3\%) & - & Tractive bronchiectasis & - & - & $9(39.1 \%)$ & - \\
\hline Streak shadow & - & - & $7(31.8 \%)$ & - & reticulation & & & & \\
\hline $\begin{array}{l}\text { Tractive bronchiectasis } \\
\text { reticulation }\end{array}$ & - & - & 9 (40.1\%) & - & $\begin{array}{l}\text { Bronchovascular } \\
\text { bundle distortion }\end{array}$ & - & - & $3(13.1 \%)$ & - \\
\hline
\end{tabular}

Bronchovascular

bundle distortion pulmonary fibrosis.

\&: Data were not available.
TABLE 1.3 | Clinical characteristics of all patients and grouped by

\section{Lung X-ray Computed Tomography}

All 40 patients completed lung CT performed by the skilled operators and the examination reports were reviewed by clinically experienced physicians. None of the patients had any disease-causing pulmonary fibrosis or was taking medications that could cause pulmonary fibrosis prior to the COVID-19 infection. The lung CT features of patients with a confirmed diagnosis of pulmonary fibrosis on examination report can be summarized as follows: ground glass opacity, fiber streak shadow, tractive bronchiectasis, reticulation, and bronchovascular bundle distortion (Thannickal et al., 2004; Meyer, 2017).

\section{Pulmonary Function Tests}

We performed pulmonary function tests (PFTs) using dry spirometry in all 40 patients. To avoid measurement errors caused by the instruments, we had conducted a professional and rigorous inspection of all the devices used in the study. PFTs and diffusing capacity of the lung for carbon monoxide (DLCO) measurements were performed according to American Thoracic Society (ATS)/China primary guidelines for routine PFTs (Culver et al., 2017; National Health Commission of the People's Reupblic of China, 2020). PFT parameters were expressed as absolute and percentage of a theoretical value calculated by Global Lung Function 2012 equations (Quanjer et al., 2012). The final measurement includes lung volume, ventilation, and diffusion function. According to the guide, the definition of ventilation dysfunction is that forced expiratory volume (FEV) 1 /forced vital capacity $(\mathrm{FVC})<70 \%$ and the definition of diffusion dysfunction is DLCO/80\% DLCO pred $<1$ (Quanjer et al., 2012; Culver et al., 2017; Dempsey and Scanlon, 2018). A professional technician reviewed the content to exclude obvious errors due to poor patient cooperation, etc. 


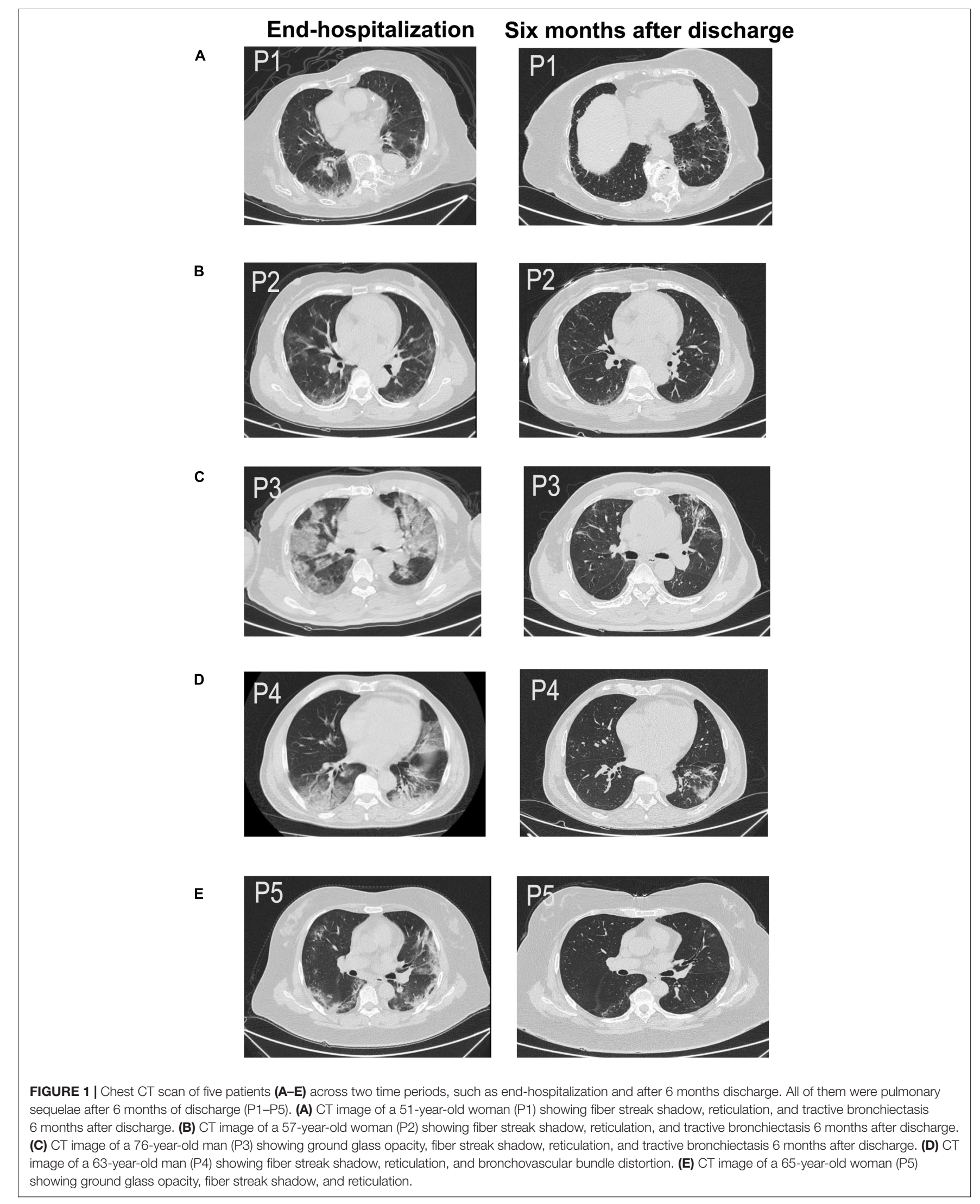



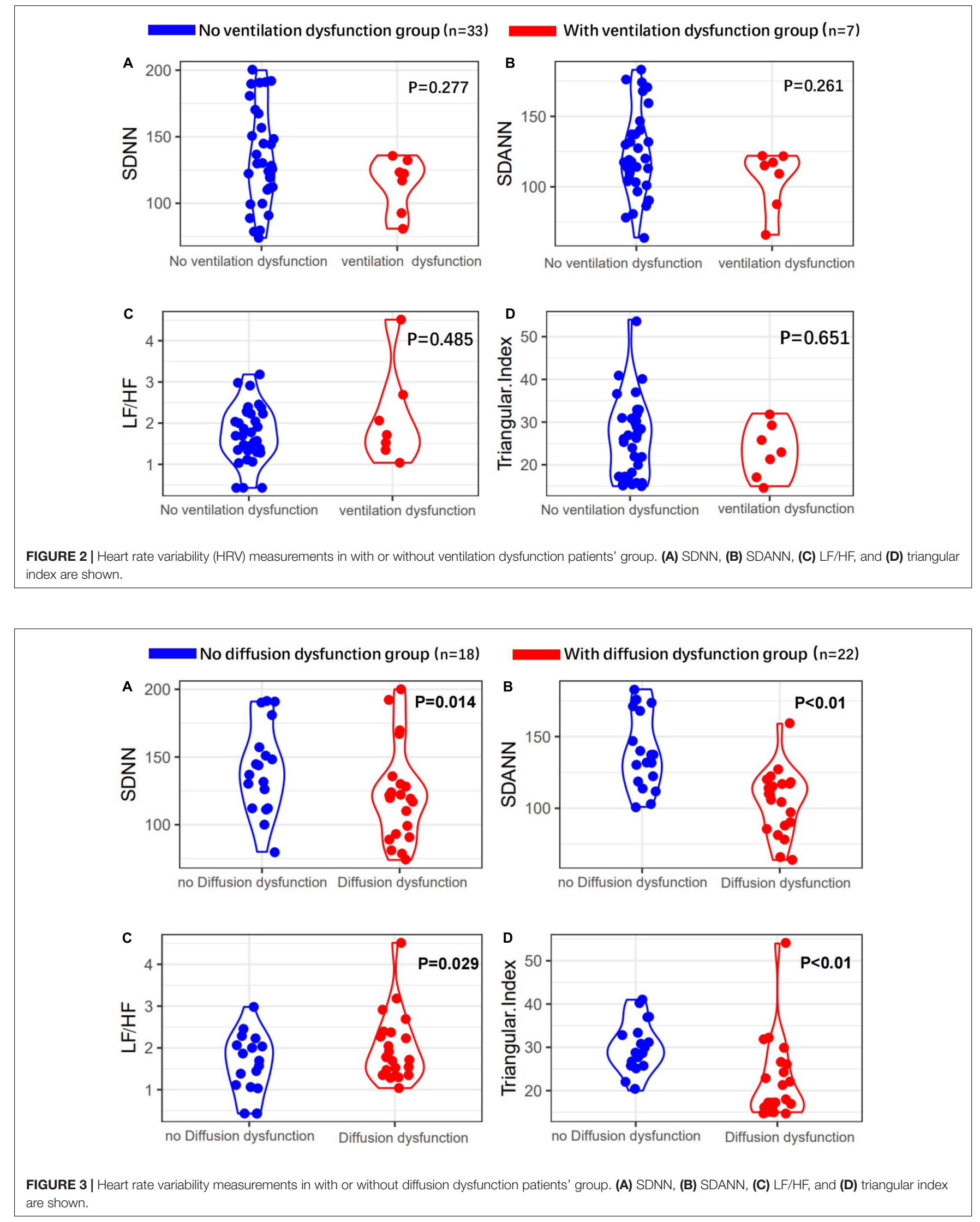
No pulmonary fibrosis group $(n=17)$

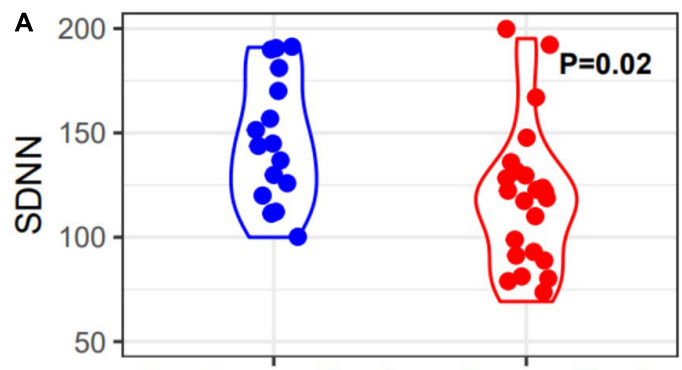

No pulmonary fibrosis pulmonary fibrosis

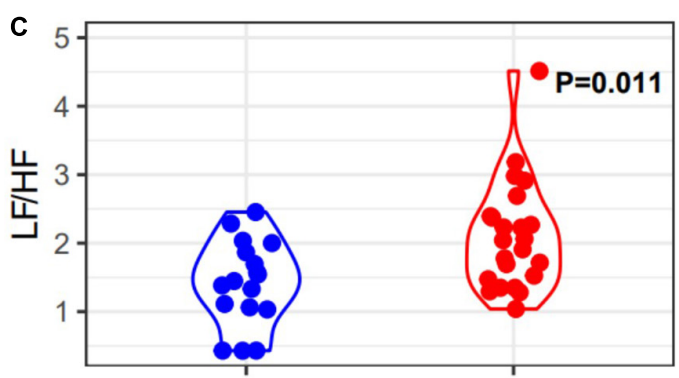

No pulmonary fibrosis pulmonary fibrosis with pulmonary fibrosis group $(n=23)$

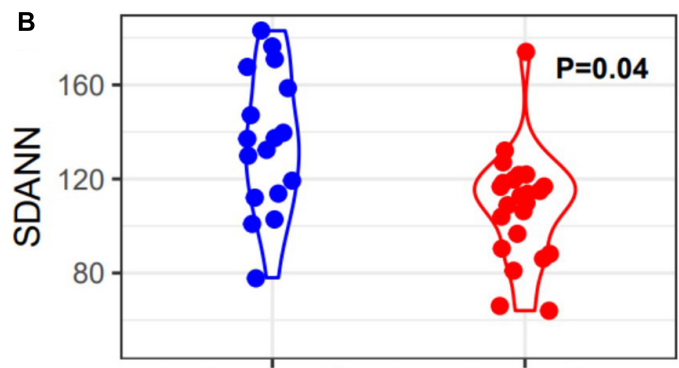

No pulmonary fibrosis pulmonary fibrosis

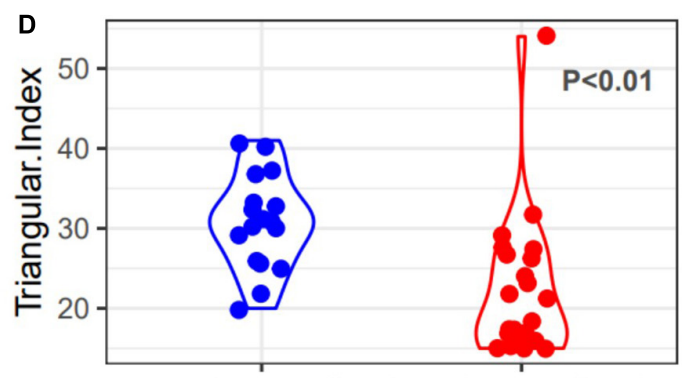

No pulmonary fibrosis pulmonary fibrosis

FIGURE 4 | Heart rate variability measurements in with or without pulmonary fibrosis patients' group. (A) SDNN, (B) SDANN, (C) LF/HF, and (D) triangular index are shown.

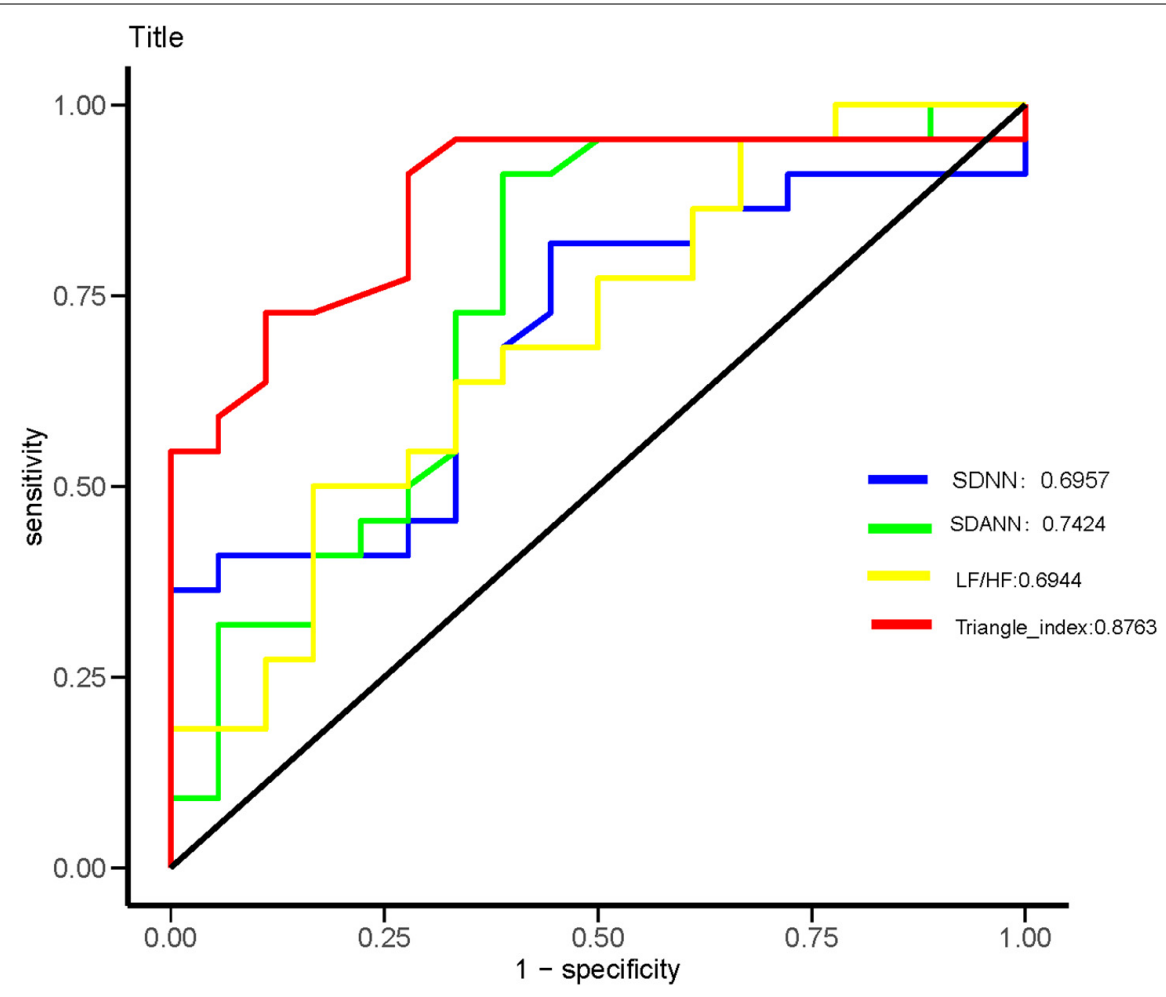

FIGURE 5 | Receiver operating characteristic (ROC) analysis for significant HRV variables. The sensitivity and specificity of SDNN, SDANN, LF/HF, and triangular index for the severity of coronavirus disease 2019 (COVID-19). 

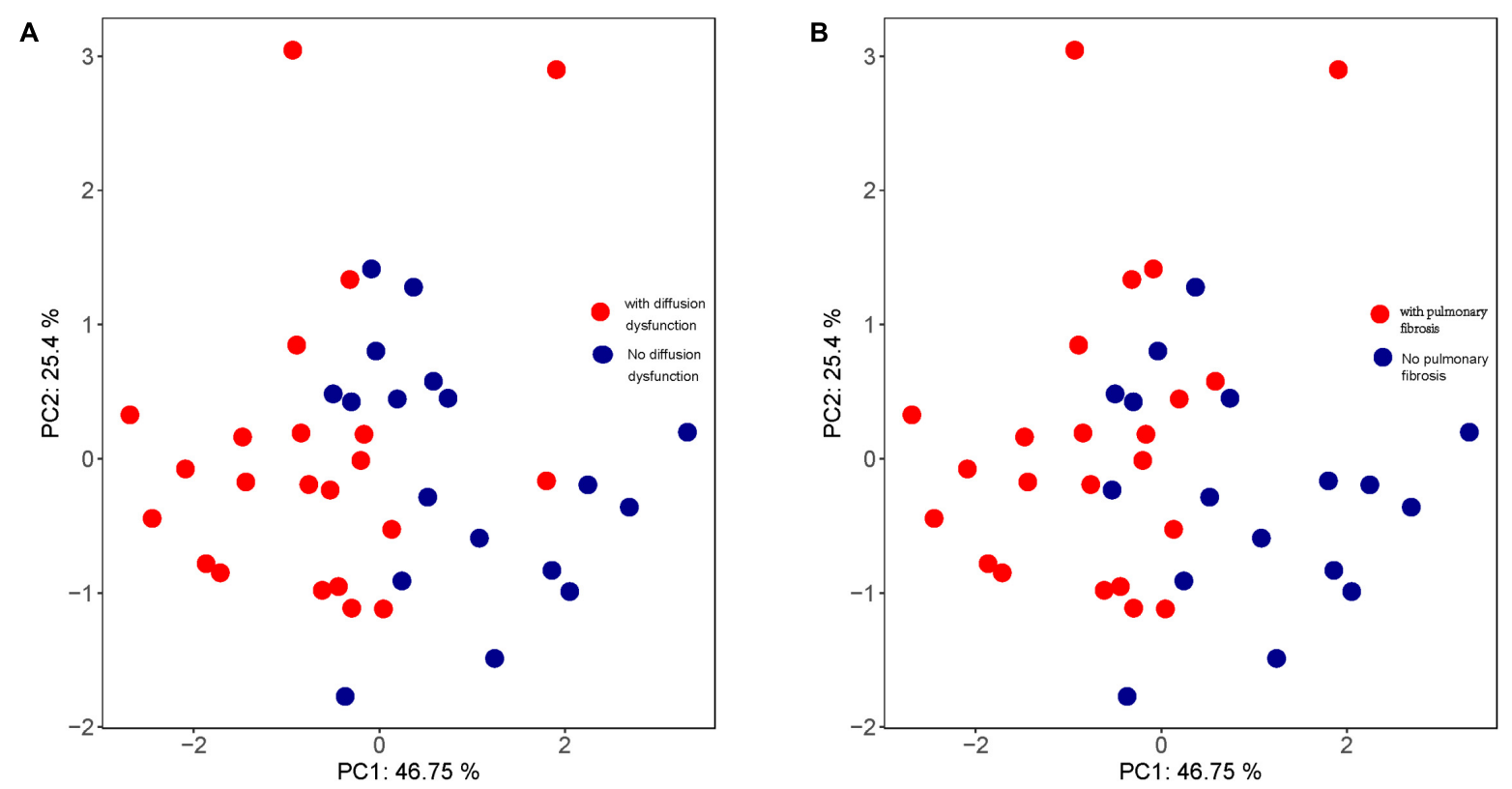

FIGURE 6 | Principal component analysis (PCA) of (A) pulmonary diffusion dysfunction and (B) pulmonary fibrosis.

We will use only the report form data signed by both the clinician and technician.

\section{Heart Rate Variability Recording}

Each patient wore a Holter detector to record ambulatory and continuous ECG data over $24 \mathrm{~h}$. ECG data, such as timeperiod, duration, value, and type of arrhythmia, were fully checked and validated by experienced physicians. Intervals with significant variations were excluded to prevent measurement operation errors. The HRV data were calculated according to the time domain analysis method, which uses the ECG waveforms measured continuously to directly calculate and analyze the relationship between the time series of connected heartbeats. These include the standard deviation of NN intervals (SDNN; normal value: $141 \pm 39 \mathrm{~ms}$; reflects total HRV); standard deviation of the average $\mathrm{NN}$ intervals (SDANN; normal value: $127 \pm 35 \mathrm{~ms}$; reflects primarily circadian HRV); the square root of the mean of the sum of the squares of differences between adjacent NN intervals (RMSSD; normal values: $27 \pm 12 \mathrm{~ms}$; reflects vagal activity); percentage differences between adjacent $\mathrm{NN}$ intervals that are greater than $50 \mathrm{~ms}$ (pNN50; normal values: $16.7 \pm 12.3 \%$; reflects vagal activity). Frequency-domain analysis included low-frequency power $0.04-0.15 \mathrm{~Hz}$ (LF; normal values: 300-1,750 $\mathrm{ms}^{2}$; reflect combination of sympathetic nervous system (SNS) and peripheral nervous system (PNS) influences, captures baroreflex rhythms), high-frequency power $0.15-0.4 \mathrm{~Hz}$ (HF; normal values: $50-120 \mathrm{~ms}^{2}$; under normal circumstances reflects vagal activity), and the ratio of low- to high-frequency power (LF/HF; normal values: $1-3$; reflect SNS/PNS balance) (Stein and $\mathrm{Pu}$, 2012; Shaffer and Ginsberg, 2017; Mejia-Mejia et al., 2020; Pan et al., 2021).

\section{Statistical Analysis}

All categorical variables were compared using the MannWhitney $U$-test or the Fisher's exact test, and all continuous variables were compared using the $t$-test, the paired $t$-test, or the Wilcoxon signed-rank test, as appropriate. Categorical data are expressed as proportions (\%). Continuous data were expressed as mean. Pearson's rank correlation and Spearman's rank correlation analysis were used for correlation analysis. Receiver operating characteristic (ROC) plots were generated evaluating four HRV indexes in predicting the pulmonary fibrosis. All statistical analyses were processed using SPSS 26.0 (IBM, Chicago, IL, United States) and R (Version 4.1.1). The $P$-value $<0.05$ was considered significant.

\section{RESULTS}

\section{Demographic and Clinical Characteristics of Participants}

We included 40 patients with COVID-19 after 6 months of discharge: the mean age was $55.1 \pm 13.9$ years, and $23(68 \%)$ were female. The mean BMI was $25.4 \pm 2.5 \mathrm{~kg} / \mathrm{m}^{2}$. In the acute phase, $14(35 \%)$ of the 40 participants were classified as mild patients and $26(65 \%)$ as severe patients. Older individuals were predominantly clinically typed as severe $(P<0.05)$. The most common symptom after discharge for 6 months was cough $(30 \%$, $12 / 40)$, followed by muscle pain $(25 \%, 10 / 40)$, diarrhea $(20 \%$, $8 / 40)$, and constipation $(20 \%, 8 / 40)$. There were $21(52.5 \%, 21 / 40)$ patients who had ARDS in the acute phase, 2 (5\%) patients had a drinking history, 7 (17.5\%) had a smoking history. About medical history, there were $5(12.5 \%)$ patients that had the cardiopulmonary disease, 14 (35\%) of them had heart disease, 

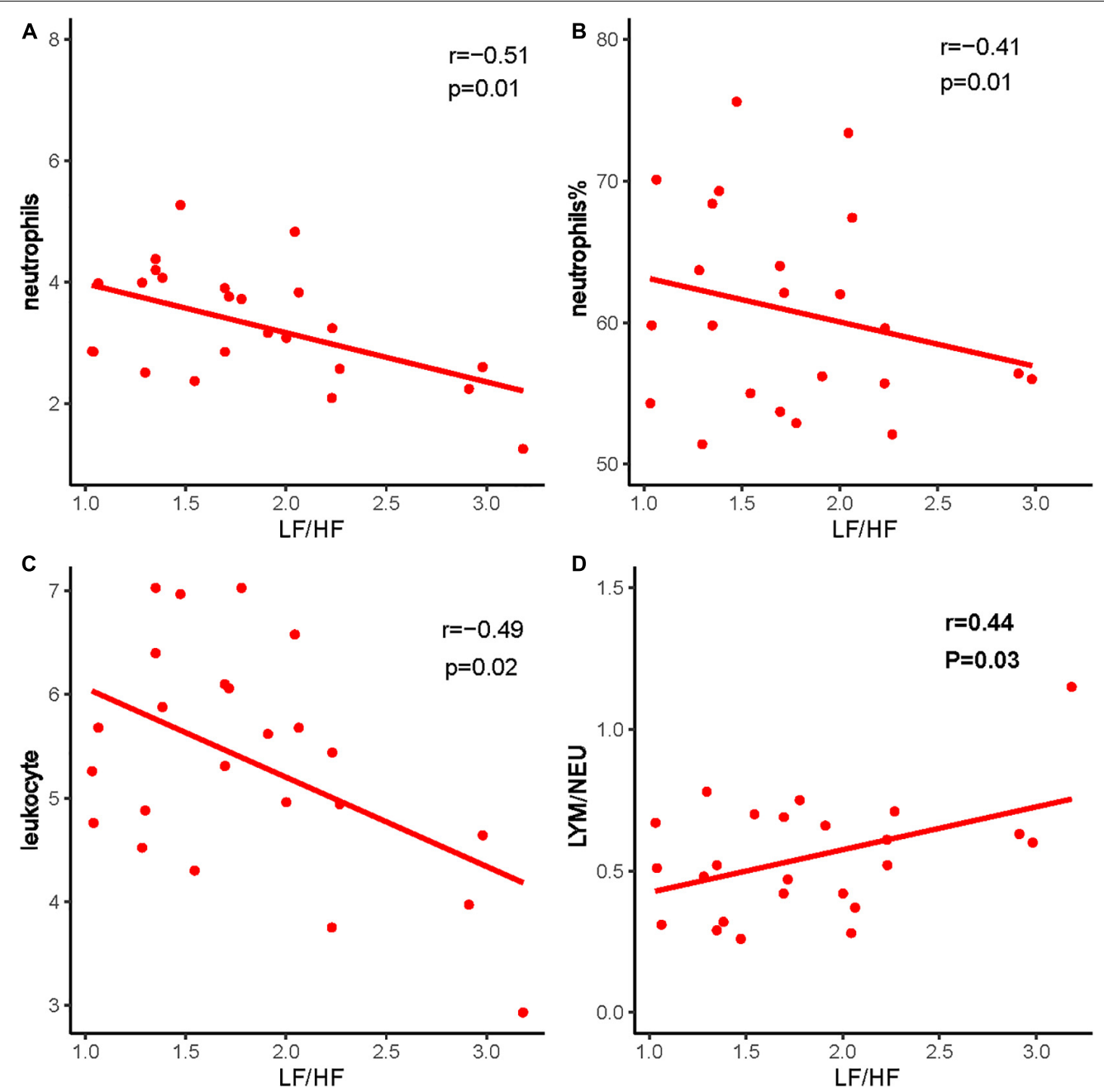

FIGURE 7 | The correlation between LF/HF and immune system indexes. (A) LF/HF and neutrophils, (B) LF/HF and neutrophils \%, (C) LF/HF and leukocyte, and (D) LF/HF and LYM/NEU. Red dots and red lines represents a patient with both HRV indicators and immune system related indicators.

12 (30\%) had hyperlipidemia, and 6 (15\%) had type 2 diabetes (Tables 1.1-1.3).

\section{Lung Function and Lung X-ray Computed Tomography Appearances of Post-discharge Participants}

First, there were seven patients $(17.5 \%)$ who had ventilation dysfunction (Table 1.1). The mean age of the ventilation disorder patients was $64.1 \pm 11.8$ years, which was not significantly correlated with the ventilation dysfunction $(P=0.162)$. The correlations between ventilation disorders and the severity of disease, ARDS, a history of smoking, and a history of alcohol consumption were not significant $(P>0.05)$. However, a history of hyperlipidemia was correlated with pulmonary ventilation dysfunction $(P=0.037)$. Pulmonary ventilation dysfunction did not associate significantly with pulmonary fibrosis, and only 7 of 23 patients with pulmonary fibrosis sequelae developed pulmonary ventilation dysfunction $(P=0.107)$.

Second, 22 patients $(55.0 \%)$ had diffusion disorder with a mean age of $62.0 \pm 9.7$ years $(P=0.001)$, being significant (Table 1.2). There were more women patients with diffusion dysfunction $(p=0.039)$. The differences between BMI, clinical typing of severe, ARDS, and past medical history were not significant $(p>0.05)$. Especially, in patients with diffusion dysfunction, breathing difficulties and cough are more apparent symptoms after 6 months of discharge. Importantly, 22 of 23 patients with COVID19 after 6 months discharge who had pulmonary fibrosis had pulmonary diffusion dysfunction, and there was a tight correlation between pulmonary fibrosis and pulmonary diffusion dysfunction $(P<0.01)$. 

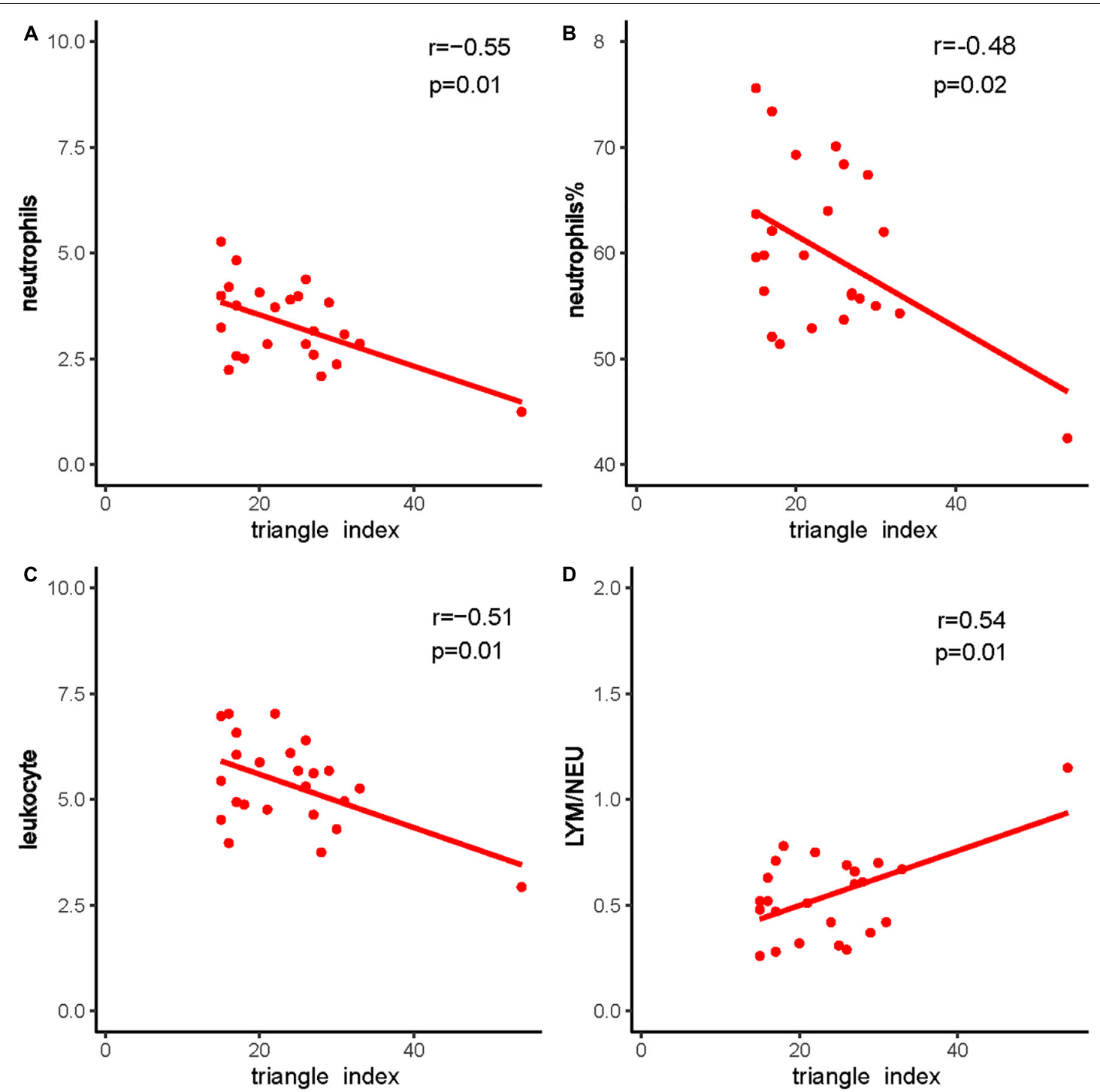

FIGURE $\mathbf{8}$ | The correlation between triangle index and immune system indexes. (A) Triangle index and neutrophils, (B) triangle index and neutrophils \%, (C) triangle index and leukocyte, and (D) triangle index and LYM/NEU. Red dots and red lines represents a patient with both HRV indicators and immune system related indicators.

Finally, pulmonary fibrosis was present in 23 of the 40 participants $(57.5 \%)$ (Table 1.3). The mean age of patients with pulmonary fibrosis was $59.7 \pm 12.5$ years, which was higher than patients without pulmonary fibrosis $(P=0.018)$. The correlation between pulmonary fibrosis and the clinical type of patients, presence of ARDS, history of smoking, history of alcohol consumption, and history of underlying diseases was not significant $(P>0.05)$.

However, we observed the CT findings of all patients with pulmonary dysfunction and found that almost all patients with diffusion dysfunction had fiber streak shadow, reticulation, ground glass opacity tractive bronchiectasis, bronchovascular bundle distortion, and other typical manifestations of pulmonary fibrosis (Figure 1): fiber streak shadow $(86.3 \%$, $19 / 22)$, reticulation $(40.1 \%, 9 / 22)$, bronchovascular bundle distortion $(36.3 \%, 8 / 22)$, ground glass opacity $(31.8 \%, 7 / 22)$, and tractive bronchiectasis $(31.8 \%, 7 / 22)$ (Table 1.2). Contrary to patients with diffusion dysfunction, the patients with ventilation dysfunction had fewer fibrosis features on CT (Table 1.1).

\section{The Correlation Among Pulmonary Fibrosis, Diffusion Dysfunction, and Heart Rate Variability}

Heart rate variability indices were tightly correlated with diffusion dysfunction and pulmonary fibrosis $(P<0.05)$ (Figures 2-4). SDNN, SDANN, and triangular index were lower in the patients with diffusion dysfunction $(P=0.014$, $P<0.01$, and $P<0.01)$, while $\mathrm{LF} / \mathrm{HF}$ was higher $(P=0.029)$. 


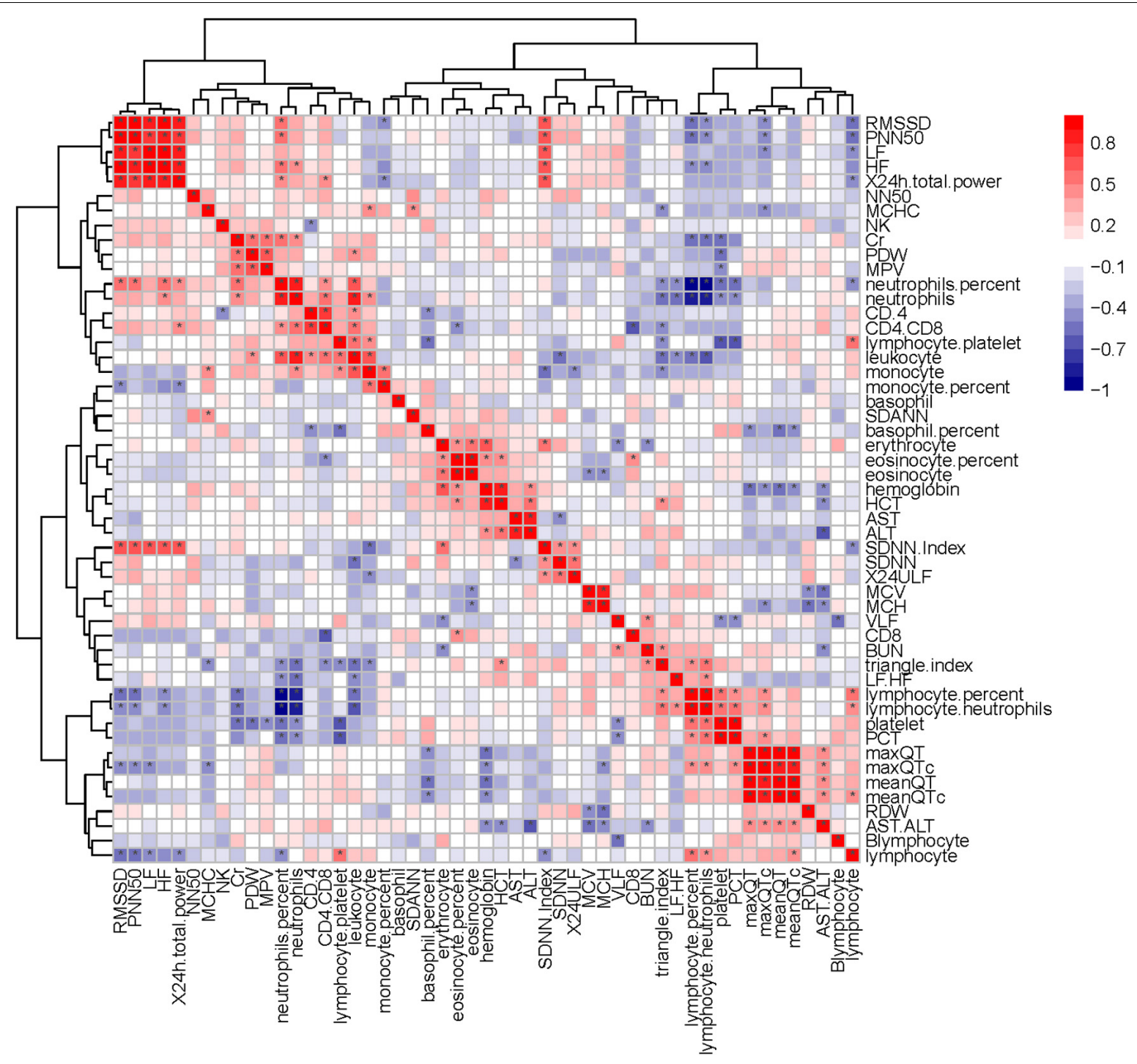

FIGURE 9 | Correlation heatmap exhibiting the relationship among routine blood parameters, liver function parameters, lymphocyte subsets, and HRV indexes in all recruited patients with COVID-19 (the asterisk means $P<0.05$ ).

The patients with pulmonary fibrosis showed the same trend as the patients with diffusion dysfunction, with lower SDNN, SDANN, triangular index, and higher LF/HF than the nonfibrosis patients $(P=0.02, P=0.04, P<0.01$, and $P=0.011$, respectively). All $P$ values were calculated excluding BMI, age, weight, and other confounding factors. To assess the diagnostic value of the SDNN, SDANN, LF/HF, and triangular index, the ROC curve analysis was the best choice. The curves of all four indicators are located above the diagonal line, indicating that all have good sensitivity and specificity. The AUC of SDNN, SDANN, LF/HF, and triangular index for pulmonary fibrosis were $0.6957,0.7424,0.6944$, and 0.8763 , respectively (Figure 5).

Moreover, the trend of HRV index changes in patients with diffusion dysfunction had the same trend as that of patients with pulmonary fibrosis (Figure 6). These results suggested that pulmonary fibrosis and diffusion dysfunction were also tightly associated.

\section{The Correlation Between Heart Rate Variability and Immune System}

Heart rate variability was correlated with the immune system. Triangle index and LF/HF showed significant negative correlations with neutrophils $(P=0.005, R=-0.552$; $P=0.010, R=-0.513)$, neutrophils \% $(P=0.019, R=-0.476$; $P=0.001, R=-0.593)$, leukocyte $(P=0.011, R=-0.511$; $P=0.016, R=-0.487)$, and positive correlations with lymphocyte/neutrophils $(P=0.006, R=0.543 ; P=0.032$, $R=0.438$ ) (Figures 7, 8). Moreover, CD4/CD8 was only tightly correlated with the triangle index. However, the correlation 


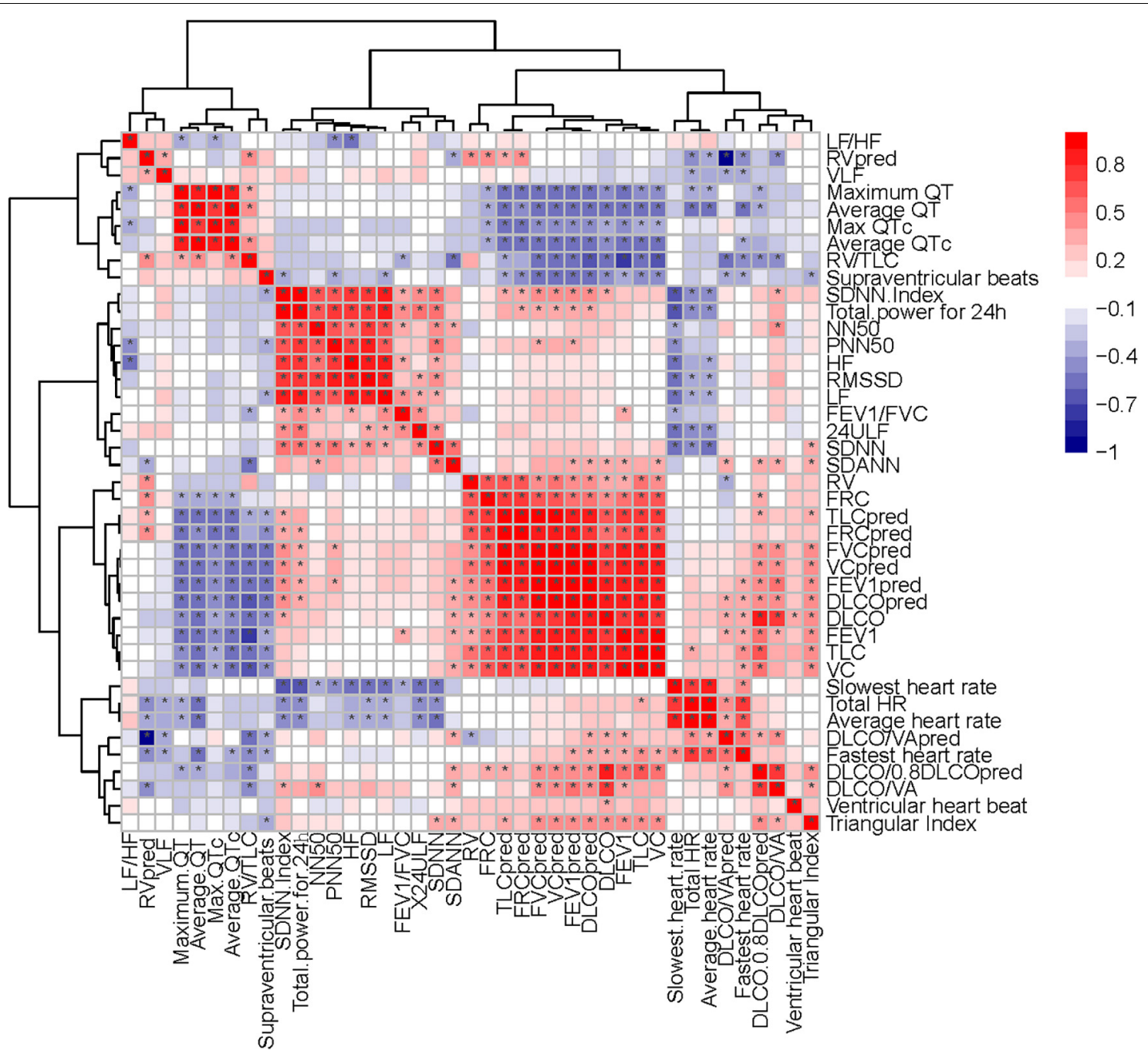

FIGURE 10 | Correlation heatmap exhibiting the relationship among pulmonary function test, diffusing capacity of the lung for carbon monoxide (DLCO) related tests and HRV indexes in all recruited patients with COVID-19 (the asterisk means $P<0.05$ ).

between SDNN and SDANN with immune-related indicators was not significant, and liver function parameters had no significant correlation (Figure 9).

\section{DISCUSSION}

This study found that autonomic dysfunction was tightly correlated with pulmonary sequelae in patients with COVID19 after 6 months of discharge. Compared with the acute phase, the ventilatory dysfunction of many patients was relieved after discharge, but more patients had pulmonary diffusion dysfunction and pulmonary fibrosis sequelae. We support that the long-term lung injury in patients with COVID-19 was dominated by diffusion dysfunction and that the structural sequelae were reflected in fibrosis. Previous studies have suggested that HRV was related to the condition of patients in the acute phase, and we found that HRV was associated with the patient condition even after discharge. Similar to the severe patients with COVID-19 in the acute phase, some HRV indexes in patients with pulmonary sequelae in the chronic phase were also decreased, such as SDNN, SDANN, and triangular index (Pan et al., 2021). Patients whose HRV did not return to normal may take longer to recover lung function. However, no previous study focuses on the association between autonomic dysfunction with the chronic phase of patients with COVID-19.

The ANS plays an essential and irreplaceable role in maintaining the balance of body (Ulrich-Lai and Herman, 2009). HRV is the fluctuation in the time interval between consecutive heartbeats, the measurement of which is a noninvasive method of assessing the autonomic status (Ponomarev et al., 2021). Studies have found that HRV changes in systemic infections and that monitoring HRV can improve the diagnosis and prognosis of infections (Barnaby et al., 2019). In addition, HRV can be considered as a possible predictive marker for the acute inflammatory response in patients with 
COVID-19 (Del Rio et al., 2020). The potential role of autonomic dysfunction may play a critical role in COVID-19 morbidity and mortality (Barizien et al., 2021). Most importantly, the latest research suggests that HRV can predict the clinical outcomes of patients in the acute phase. In addition, dysautonomia may explain the persistent symptoms observed in long duration patients with COVID-19, such as fatigue (Wiersinga et al., 2020). So, our research innovatively studied the association between HRV and pulmonary sequelae.

Our results suggest that there is a potential correlation between chronic autonomic disorder and pulmonary fibrosis and HRV can be used as a non-invasive predictor of clinical outcome in the patients with COVID-19 after acute phases. Endothelial barrier disruption, dysfunctional alveolar-capillary oxygen transmission, and impaired oxygen diffusion capacity are collectively characteristic features of patients with COVID-19 in the acute phase. However, due to these characteristics, patients in the acute phase were often in a state of hypoxia or stress and had a faster breathing rate. HRV indexes were temporarily affected by these factors (Baptista et al., 2020; Wiersinga et al., 2020; Pan et al., 2021). Compared with in-hospital, all patients included in our study had normal blood oxygen saturation and their psychological pressure had also been reduced a lot so that we can reduce at least two acute interference factors (hypoxia and stress) on HRV (Leung et al., 2020; Wang et al., 2020). Therefore, HRV can more genuinely reflect the function of the ANS. Additionally, we excluded the underlying disease, weight, gender, age, and other possible interfering factors in the calculation. In addition, we selected four credible, representative, and widely used indicators as the main research objects: SANN and SDANN are very representative of the overall changes in HRV, and the triangular index is for the overall assessment of HRV from a geometric perspective, LF/HF can reflect changes in autonomic nerve function, especially LF/HF which has been widely used in the evaluation of condition of patients with sleep disorders and depression (Boudreau et al., 2013; Sgoifo et al., 2015; Shaffer and Ginsberg, 2017). Therefore, our results can more accurately investigate the correlation between long-term lung damage caused by COVID-19 infection and autonomic dysfunction. In addition, our results agreed with previous followup studies that autonomic long-term lung injury in patients with COVID-19 is dominated by diffusion dysfunction and pulmonary fibrosis (Faverio et al., 2021; Huang et al., 2021; Shah et al., 2021).

The ANS is closely associated with many regulating mechanisms, such as the immune system (e.g., CD4/CD8, lymphocyte, and neutrophils) (Kenney and Ganta, 2014; Wu et al., 2021). Some researchers believe that the COVID-19 can affect the condition of patient by affecting the immune system and HRV also related to immune system changes (Ahmad et al., 2009; Chowdhury et al., 2020; Tahaghoghi-Hajghorbani et al., 2020; Hasty et al., 2021). Our result suggests that HRV was indeed correlated with some immune system indicators, such as CD4/CD8 was correlated with the triangular index $(P<0.05)$ (Figure 9). Furthermore, PFTs were correlated with some immune system indexes, such as neutrophils and monocyte $(P<0.05)$ (Supplementary Figure 1). Therefore, our study may provide evidence that the immune system was interfered with COVID-19 and offer new ideas for the treatment of pulmonary fibrosis.

Heart rate variability-evaluation, as widely accepted and noninvasive, is cost-neutral and available for use under-study and clinical conditions (Xhyheri et al., 2012; Natarajan et al., 2020). In this study, we found that HRV was correlated with pulmonary fibrosis, pulmonary diffusion dysfunction, and immune system (Figures 9, 10). Thus, HRV should be considered when evaluating the therapeutic approaches of COVID-19. Patients with faster recovery from HRV often do not have pulmonary fibrosis. Not only pulmonary sequelae, previous studies indicated that immune system factors are inevitably linked to a wellbalanced ANS (Czura and Tracey, 2005). Patients with more severe autonomic dysfunction will have a greater probability of pulmonary sequelae, but the development of pulmonary sequelae is not only affected by one factor. Long-term COVID-19 infected may lead to various immune system reactions, which can affect autonomic nerve activity (Wu et al., 2021). Direct viral invasion of neural parenchyma or via retrograde axonal transport could be a mechanism, too (Koralnik and Tyler, 2020). In some related diseases, the vagus nerve stimulation has been used as a part of the therapeutic approach (Baptista et al., 2020). Therefore, HRV indicators, immune related treatments, and vagus nerve stimulation (VNS) treatment methods can be considered in the process of rehabilitation of patients with COVID-19.

At present, the global research on the health of patients with COVID-19 after discharge is still in its infancy. The tight correlation between HRV and pulmonary fibrosis, lung function, immune system, and other symptoms after the acute phase is worthy of attention.

Our findings are preliminary, and our study is just based on a small sample of patients with COVID-19 in one hospital. If the sample size is large enough, there may be more in-depth discoveries. But the limitation does not affect the conclusion of the article, because based on the current data, it has been able to prove the correlation between the key indicators. To make the association between pulmonary fibrosis and HRV more valuable for clinical or research in the future, we could design a cohort study to discuss whether HRV can predict chronic patient outcomes.

\section{CONCLUSION}

This study showed that autonomic dysfunction is significantly correlated with pulmonary diffusion dysfunction and pulmonary fibrosis after discharge among patients with COVID-19, and immune mechanisms may be correlated with the autonomic dysfunction and may play a potential role between the ANS and pulmonary sequelae.

\section{DATA AVAILABILITY STATEMENT}

The raw data supporting the conclusions of this article will be made available by the authors, without undue reservation. 


\section{ETHICS STATEMENT}

The studies involving human participants were reviewed and approved by the Research Ethics Commission of Wuhan Union Hospital. The patients/participants provided their written informed consent to participate in this study.

\section{AUTHOR CONTRIBUTIONS}

$\mathrm{XH}$ and YM developed the main idea of this study. TB developed the search strategy. DaZ independently completed the selection of studies, data extraction, assessment of risk of bias, and data synthesis. FY and DW arbitrated the disagreements and drafted and revised the original manuscript. All authors have read and approved the final manuscript.

\section{FUNDING}

This study was supported by the grants of two Novel Coronavirus Pneumonia Emergency Science and Technology projects from

\section{REFERENCES}

Ahmad, S., Tejuja, A., Newman, K. D., Zarychanski, R., and Je Seely, A. (2009). Clinical review: a review and analysis of heart rate variability and the diagnosis and prognosis of infection. Crit. Care 13:232. doi: 10.1186/ cc8132

Baptista, A. F., Baltar, A., Okano, A. H., Moreira, A., Pinheiro Campos, A. C., Fernandes, A. M., et al. (2020). Applications of non-invasive neuromodulation for the management of disorders related to COVID-19. Front. Neurol. 11:573718. doi: 10.3389/fneur.2020.573718

Barizien, N., Le Guen, M., Russel, S., Touche, P., Huang, F., Vallée, A., et al. (2021). Clinical characterization of dysautonomia in long COVID-19 patients. Sci. Rep. 11:14042. doi: 10.1038/s41598-021-93546-5

Barnaby, D. P., Fernando, S. M., and Herry, C. L. (2019). Heart rate variability, clinical and laboratory measures to predict future deterioration in patients presenting with sepsis. Shock 51, 416-422. doi: 10.1097/SHK. 0000000000001192

Boudreau, P., Yeh, W. H., Dumont, G. A., and Boivin, D. B. (2013). Circadian variation of heart rate variability across sleep stages. Sleep 36, 1919-1928. doi: 10.5665/sleep.3230

Chowdhury, M. A., Hossain, N., Kashem, M. A., Shahid, M. A., and Alam, A. (2020). Immune response in COVID-19: a review. J. Infect. Public Health 13, 1619-1629. doi: 10.1016/j.jiph.2020.07.001

Culver, B. H., Graham, B. L., and Coates, A. L. (2017). Recommendations for a standardized pulmonary function report. an official american thoracic society technical statement. Am. J. Respir. Crit. Care Med. 196, 1463-1472. doi: 10.1164/ rccm.201710-1981ST

Czura, C. J., and Tracey, K. J. (2005). Autonomic neural regulation of immunity. J. Intern. Med. 257, 156-166. doi: 10.1111/j.1365-2796.2004.01442.x

Dani, M., Dirksen, A., Taraborrelli, P., Torocastro, M., Panagopoulos, D., Sutton, R., et al. (2021). Autonomic dysfunction in 'long COVID': rationale, physiology and management strategies. Clin. Med. (Lond.) 21, e63-e67. doi: 10.7861/ clinmed.2020-0896

Del Rio, R., Marcus, N. J., and Inestrosa, N. C. (2020). Potential role of autonomic dysfunction in Covid-19 morbidity and mortality. Front. Physiol. 11:561749. doi: 10.3389/fphys.2020.561749

Dempsey, T. M., and Scanlon, P. D. (2018). Pulmonary function tests for the generalist: a brief review. Mayo Clin. Proc. 93, 763-771. doi: 10.1016/j.mayocp. 2018.04.009 the Science and Technology Department of Hubei Province, Wuhan, China (2020FCA014 and 2021CFB809) and partly supported by the National Natural Science Foundation of China (Nos. 81720108006, 81800467, and 81974062).

\section{ACKNOWLEDGMENTS}

We are very grateful to acknowledge the reviewers for their helpful comments on this manuscript.

\section{SUPPLEMENTARY MATERIAL}

The Supplementary Material for this article can be found online at: https://www.frontiersin.org/articles/10.3389/fphys. 2021.805925/full\#supplementary-material

Supplementary Figure 1 | Correlation heatmap exhibiting the relationship between pulmonary function test, diffusing capacity of the lung for carbon monoxide (DLCO) related tests, immune system indexes and liver function tests in all recruited patients with coronavirus disease 2019 (COVID-19) (the asterisk means $P<0.05)$.

Fan, E., Brodie, D., and Slutsky, A. S. (2018). Acute respiratory distress syndrome: advances in diagnosis and treatment. JAMA 319, 698-710. doi: 10.1001/jama. 2017.21907

Faverio, P., Luppi, F., Rebora, P., Busnelli, S., Stainer, A., Catalano, M., et al. (2021). Six-Month pulmonary impairment after severe COVID-19: a prospective, multicentre follow-up study. Respiration 100, 1078-1087. doi: 10. $1159 / 000518141$

Hasty, F., Garcia, G., Davila, C. H., Wittels, S. H., Hendricks, S., Chong, S., et al. (2021). Heart rate variability as a possible predictive marker for acute inflammatory response in COVID-19 patients. Mil. Med. 186, e34-e38. doi: 10.1093/milmed/usaa405

Huang, C., Huang, L., Wang, Y., Li, X., Ren, L., Gu, X., et al. (2021). 6-month consequences of COVID-19 in patients discharged from hospital: a cohort study. Lancet 397, 220-232. doi: 10.1016/S0140-6736(20)32656-8

Jing-Ya, Z., Jia-Yang, Y., and Jie-Ming, Q. (2020). Diagnosis and treatment protocol for novel coronavirus pneumonia (Trial Version 7). Chin. Med. J. (Engl) 133, 1087-1095. doi: 10.1097/CM9.0000000000000819

Kenney, M. J., and Ganta, C. K. (2014). Autonomic nervous system and immune system interactions. Compr. Physiol. 4, 1177-1200. doi: 10.1002/cphy.c130051

Koralnik, I. J., and Tyler, K. L. (2020). COVID-19: a global threat to the nervous system. Ann. Neurol. 88, 1-11. doi: 10.1002/ana.25807

Lee, J. Y. T., Tikellis, G., Corte, T. J., Goh, N. S., Keir, G. J., Spencer, L., et al. (2020). The supportive care needs of people living with pulmonary fibrosis and their caregivers: a systematic review. Eur. Respir Rev. 29:190125. doi: 10.1183/ 16000617.0125-2019

Leung, T. Y. M., Chan, A. Y. L., and Chan, E. W. (2020). Short- and potential longterm adverse health outcomes of COVID-19: a rapid review. Emerg. Microbes Infect. 9, 2190-2199. doi: 10.1080/22221751.2020.1825914

Lewis, K. L., Helgeson, S. A., Tatari, M. M., Mallea, J. M., Baig, H. Z., Patel, N. M., et al. (2021). COVID-19 and the effects on pulmonary function following infection: a retrospective analysis. EClinicalMedicine 39:101079. doi: 10.1016/j. eclinm.2021.101079

Luong, A., Goodyke, M., Dunn, S. L., Baynard, T., and Bronas, U. (2021). ActiGraph and short-term heart rate variability study protocol: amended for the COVID-19 pandemic. J. Cardiovasc. Nurs. 36, 599-608. doi: 10.1097/JCN. 0000000000000817

McDonald, L. T. (2021). Healing after COVID-19: are survivors at risk for pulmonary fibrosis? Am. J. Physiol. Lung Cell Mol. Physiol. 320, L257-L265. doi: 10.1152/ajplung.00238.2020 
Mejia-Mejia, E., Budidha, K., Abay, T. Y., May, J. M., and Kyriacou, P. A. (2020). Heart Rate Variability (HRV) and Pulse Rate Variability (PRV) for the assessment of autonomic responses. Front. Physiol. 11:779. doi: 10.3389/fphys. 2020.00779

Meyer, K. C. (2017). Pulmonary fibrosis, part I: epidemiology, pathogenesis, and diagnosis. Expert Rev. Respir Med. 11, 343-359. doi: 10.1080/17476348.2017. 1312346

Natarajan, A., Su, H. W., and Heneghan, C. (2020). Assessment of physiological signs associated with COVID-19 measured using wearable devices. NPJ Digit. Med. 3:156. doi: 10.1038/s41746-020-00363-7

National Health Commission of the People's Reupblic of China (2020). "Handbook of prevention and treatment of the pneumonia caused by the Novel Coronavirus (2019-nCoV)," National Health Commission of the People's Reupblic of China. Available online at: http://en.nhc.gov.cn/2020-02/06/c 76295.htm (accessed February 6, 2020).

Pan, Y., Yu, Z., Yuan, Y., Han, J., Wang, Z., Chen, H., et al. (2021). Alteration of autonomic nervous system is associated with severity and outcomes in patients with COVID-19. Front. Physiol. 12:630038. doi: 10.3389/fphys.2021.630038

Ponomarev, A., Tyapochkin, K., Surkova, E., Smorodnikova, E., and Pravdin, P. (2021). Heart rate variability as a prospective predictor of early COVID-19 symptoms. medRxiv [Preprint] doi: 10.1101/2021.07.02.21259891

Quanjer, P. H., Stanojevic, S., Cole, T. J., Baur, X., Hall, G. L., Culver, B. H., et al. (2012). Multi-ethnic reference values for spirometry for the 3-95-yr age range: the global lung function 2012 equations. Eur. Respiratory J. 40, 1324-1343. doi: 10.1183/09031936.00080312

Safont, B., Tarraso, J., Rodriguez-Borja, E., Fernández-Fabrellas, E., Sancho-Chust, J. N., Molina, V., et al. (2021). Lung function, radiological findings and biomarkers of fibrogenesis in a cohort of COVID-19 patients six months after hospital discharge. Arch. Bronconeumol. (Engl. Ed) [Online ahead of print] doi: 10.1016/j.arbres.2021.08.014

Sgoifo, A., Carnevali, L., and Alfonso Mde, L. (2015). Autonomic dysfunction and heart rate variability in depression. Stress 18 , 343-352. doi: 10.3109/10253890. 2015.1045868

Shaffer, F., and Ginsberg, J. P. (2017). An overview of heart rate variability metrics and norms. Front. Public Health 5:258. doi: 10.3389/fpubh.2017.0 0258

Shah, A. S., Ryu, M. H., Hague, C. J., Murphy, D. T., Johnston, J. C., Ryerson, C. J., et al. (2021). Changes in pulmonary function and patient-reported outcomes during COVID-19 recovery: a longitudinal, prospective cohort study. ERJ Open Res. 7, 00243-2021. doi: 10.1183/23120541.00243-2021

Stein, P. K., and Pu, Y. (2012). Heart rate variability, sleep and sleep disorders. Sleep Med. Rev. 16, 47-66. doi: 10.1016/j.smrv.2011.02.005

Tahaghoghi-Hajghorbani, S., Zafari, P., Masoumi, E., Rajabinejad, M., JafariShakib, R., Hasani, B., et al. (2020). The role of dysregulated immune responses in COVID-19 pathogenesis. Virus Res. 290:198197. doi: 10.1016/j.virusres.2020. 198197

Thannickal, V. J., Toews, G. B., White, E. S., Lynch, J. P., and Martinez, F. J. (2004). Mechanisms of pulmonary fibrosis. Annu. Rev. Med. 55, 395-417. doi: 10.1146/annurev.med.55.091902.103810

Ulrich-Lai, Y. M., and Herman, J. P. (2009). Neural regulation of endocrine and autonomic stress responses. Nat. Rev. Neurosci. 10, 397-409. doi: 10.1038/ nrn2647

Wang, F., Kream, R. M., and Stefano, G. B. (2020). Long-Term respiratory and neurological sequelae of COVID-19. Med. Sci. Monit. 26:e928996. doi: 10. 12659/MSM.928996

Wiersinga, W. J., Rhodes, A., Cheng, A. C., Peacock, S. J., and Prescott, H. C. (2020). Pathophysiology, transmission, diagnosis, and treatment of coronavirus disease 2019 (COVID-19): a review. JAMA 324, 782-793. doi: 10.1001/jama. 2020.12839

Wu, J., Tang, L., Ma, Y., Li, Y., Zhang, D., Li, Q., et al. (2021). Immunological profiling of COVID-19 patients with pulmonary sequelae. mBio 12:e0159921. doi: 10.1128/mBio.01599-21

Xhyheri, B., Manfrini, O., Mazzolini, M., Pizzi, C., and Bugiardini, R. (2012). Heart rate variability today. Prog. Cardiovasc. Dis. 55, 321-331. doi: 10.1016/j.pcad. 2012.09.001

Zhao, Y. M., Shang, Y. M., Song, W. B., Li, Q. Q., Xie, H., Xu, Q. F., et al. (2020). Follow-up study of the pulmonary function and related physiological characteristics of COVID-19 survivors three months after recovery. EClinicalMedicine 25:100463. doi: 10.1016/j.eclinm.2020. 100463

Conflict of Interest: The authors declare that the research was conducted in the absence of any commercial or financial relationships that could be construed as a potential conflict of interest.

Publisher's Note: All claims expressed in this article are solely those of the authors and do not necessarily represent those of their affiliated organizations, or those of the publisher, the editors and the reviewers. Any product that may be evaluated in this article, or claim that may be made by its manufacturer, is not guaranteed or endorsed by the publisher.

Copyright (c) 2022 Bai, Zhou, Yushanjiang, Wang, Zhang, Liu, Song, Zhang, Hou and Ma. This is an open-access article distributed under the terms of the Creative Commons Attribution License (CC BY). The use, distribution or reproduction in other forums is permitted, provided the original author(s) and the copyright owner(s) are credited and that the original publication in this journal is cited, in accordance with accepted academic practice. No use, distribution or reproduction is permitted which does not comply with these terms. 